\title{
THE TRANSNASAL APPROACH TO SELLAR LESIONS. A NEUROSURGICAL EXPERIENCE AND PERSPECTIVE
}

\author{
Syed Sarmad Bukhari, Anisa Kalsoom*, Muhammad Junaid**, Maqbool Raza** \\ The Aga Khan University Hospital, Karachi, Pakistan, *Fauji Foundation Hospital, Rawalpindi Pakistan, ${ }^{* *}$ Combined Military Hospital, Multan/National \\ University of Medical Sciences (NUMS) Pakistan
}

\begin{abstract}
The transnasal approach for pituitary lesions has been adopted increasingly by neurosurgeons for removing sellar lesions. It has made surgery in this region safer with fewer complications in experienced hands. However, the approach requires good knowledge of nasal anatomy and formal training to achieve good results since the territory is unfamiliar to most neurosurgeons. The approach has a somewhat steep learning curve. In our experience of 41 cases, we have presented here. We have discussed the history of this approach, technique and relevant complications and their avoidance.
\end{abstract}

Keywords: Pituitary gland, Transnasal, Transsphenoidal.

How to Cite This Article: Bukhari SS, Kalsoom A, Junaid M, Raza M. The Transnasal Approach to Sellar Lesions. A Neurosurgical Experience and Perspective. Pak Armed Forces Med J 2021; 71 (Suppl-3): S634-636 Doi: https://doi.org/10.51253/pafmj.v1i1.7914

This is an Open Access article distributed under the terms of the Creative Commons Attribution License (https://creativecommons.org/licenses/by-nc/4.0/), which permits unrestricted use, distribution, and reproduction in any medium, provided the original work is properly cited.

\section{INTRODUCTION}

The idea that the pituitary gland is involved in pathologies was first put forward by Pierre Marie in 1886 when a description of two patients with acromegaly was published with enlarged pituitary glands. ${ }^{1}$ Marie thought that the enlargement was part of the disease process of acromegaly and not the cause. It was not until 1910 that pituitary adenomas were described as causing acromegaly. Initial attempts to approach the sellaturcica were made transcranially but over the years many other approaches were tried and described. These included the subtemporal, subfrontal and various other transcranial approaches. ${ }^{2,3}$ These approaches were met with prohibitive complication rates including mortality rates varying between $20-80 \% .4,5$

The transnasal route was popularized due to its safety profile over the last 50 years. The first transnasal trans-sphenoidal removal of a pituitary adenoma was reported by Schloffer in 1907. This was followed up over the next several years with multiple surgeons making several improvements to the approach. This was helped through collaborations with otorhinolaryngologists. $6-8$

Here we present our local experience with these tumors and provide a brief outline of the transnasal approach with its technique and attendant complication as well as complication avoidance.

\section{Our Experience}

Between 2017 and 2020, the senior surgeon

Correspondence: Dr Syed Sarmad Bukhari, Chief Resident of NeuroSurgery, The Aga Khan University and Hospital, Karachi Pakistan operated on 41 cases of sellar lesions at a tertiary care referral center. Out of $25(61 \%)$ were male and $16(39 \%)$ were female. Patients hailed from almost all parts of the country and demographics varied. No ENT surgeon was involved in the procedures. Out of $28(56 \%)$ were non-functioning adenomas, $11(27 \%)$ were growth hormone secreting adenomas while the rest were prolactinaoma (2 cases).

\section{DISCUSSION}

\section{A Brief History of The Transnasal Approach}

Following Schloffer's description of his technique, several surgeons opted to use the sublabial incision and approach under local anesthesia for its superior cosmetic results. However, the majority of refinement in the transnasal approach was achieved by Harvey Cushing in his series of over 200 cases. He was able to lower the mortality to $5.6 \%$ in his series but was irked by frequent meningitis and CSF leaks. This led to him subsequently abandoning the approach in favor of a transcranial approach due his lowered mortality rate with this approach. ${ }^{9}$ This was also not helped by a lack of familiarity amongst neurosurgeons with the nose and nasal anatomy. In the UK, Norman Dott continued his use of the transnasal approach which faced a resurgence in the 1950s. This was due to enhanced safety of the approach with widespread availability of antibiotics reducing the risk of meningitis as well as corticosteroids for pituitary replacement. Another important factor in the perfection of the approach was the use of the operating microscope and fluoroscopic guidance (Hardy) which allowed careful localization of the sella and avoidance of CSF leak. The current mortality of 
transnasal trans-sphenoidal surgery stands between $0 \%$ and $1 \% .{ }^{10-13}$

\section{The Nose for Neurosurgeons}

The transnasal approach for pituitary tumors has historically been learnt and performed entirely by neurosurgeons. However, in the modern era of specialization, more and more tertiary care centers request and ENT surgeon to start the case after positioning. The ENT surgeon will 'make the approach' up till the floor of the sella. The ENT surgeon will also raise a vascularized nasoseptal flap for subsequent covering of the defect in the roof of the sphenoid sinus. This allows the neurosurgeon to have more confidence when starting removal of the floor due the ENT surgeon's vast experience of this area. ${ }^{14}$ In the experience of the senior author however, an ENT surgeon was not involved in his practice of transnasal surgery. Neurosurgeons in the developing world need to be acutely aware that having an ENT colleague by your side may be a luxury that can be cost prohibitive to the patient especially when the approach can be safely done by a properly trained neurosurgeon. We make no recommendations for or against this practice.

Anatomy relevant to the transnasal approach should be familiar to the neurosurgeon. The air spaces of relevance are the nasal cavity which extends from the anterior nares to the choanae posteriorly. The approach in itself is divided into three stages; nasal, sphenoidal and sellar. The nasal cavity is divided into three horizontal spaces by the turbinates, superior, middle and inferior with the anterior wall of the sphenoid sinus being in relation to the middle turbinate. The nasal septum divides it into right and left halves. The nasal septum may be deviated resulting in confusion of the midline. Fluoroscopy and neuronavigation can be quite useful for midline orientation. The superior limit of the opening into the sphenoid sinus is marked by the sphenoid ostium on each side in the sphenopalatine recess. ${ }^{15}$

A careful preoperative review of sphenoid sinus anatomy needs to be done for variations (sellar, presellar and conchal) that would complicate the approach. ${ }^{15}$ Removal of the anterior wall of the sphenoid fossa reveals the posterior wall which forms the floor of the pituitary fossa. Superior and anterior to this landmark, the skull base continues as the tuberculum sellae and planum sphenoidale. A bulge of bone marks the location of the carotid artery on each side. The opticocarotid recess is frequently seen as the bony depression on the supero-lateral aspect of the sphenoid sinus that demarcate the optic nerve from the carotid arteries. ${ }^{14}$

\section{The Nasal Approach for Neurosurgeons}

The operation is now performed under general anesthesia with the patient in the supine position and head placed in a horseshoe or head ring according to surgeon preference. A three pin head holder (Mayfield) is required for cases needing neuronavigation. We recommend the use of image guidance in all cases of challenging sellar anatomy and redo cases to avoid intraoperative confusion. Steroid and perioperative antibiotic prophylaxis is as per institutional protocol. We prefer to soak both sides of the nasal cavity with xylometazoline solution prior to pyodine preparation. Mustache and nasal hair may be trimmed. Some ENT surgeons may even forego such preparations. The head is positioned either neutral or slightly tilted towards the right for a right nostril approach for a right handed surgeon.

At this point there is an option of either using a microscope, an endoscope or both for building our approach. Each instrument has its own benefits and drawbacks, a detailed decription of which is outside the scope of this text. ${ }^{16} \mathrm{~A}$ uninostril approach is usually all that is needed but wider exposures can be made using a binostril approach. Two steps are important in increasing the working space inside the nose, lateralization of the middle turbinate and fracture of the vomer with contralateral movement. This allows visualization of both sphenoid ostia. A subperiosteal flap is raised based on the sphenopalatine artery depending on surgeon preference. The floor of the sphenoid sinus is then removed with a drill or rongeurs.

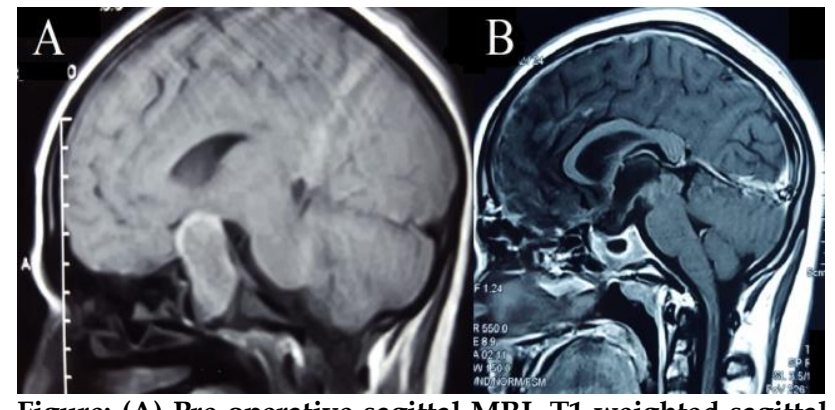

Figure: (A) Pre-operative sagittal MRI, T1 weighted sagittal image showing a sellar and suprasellar mass with postgadolinium enhancement. (B) Post-operative T1 weighted post contrast image showing interval resection of the lesion through transnasal approach.

\section{Extended Nasal Approaches}

The use of the endoscope has allowed surgeons to develop so called extended approaches for parasellar 
and anterior skull base lesions. These are specialized approaches and we recommend that surgeons who wish to undertake them be formally trained with a mentor due to the steep learning curve.

\section{Nasal Complications}

Cheng et al, have written a detailed account of nasal complications (Table) after transnasal surgery for pituitary lesions. The list of complications they have described are; nasal hemorrhage, CSF rhinorrhea, sphenoid sinusitis, atrophic rhinitis, olfactory disorder, nasal septum perforation and nasal adhesions. ${ }^{17,18}$

Table: Nasal complications and their management.

\begin{tabular}{l|l|l}
\hline Complication & Management & Avoidance \\
\hline Hemorrhage & $\begin{array}{l}\text { Electrocoagulation, } \\
\text { packing and rarely, } \\
\text { embolization for } \\
\text { traumatic } \\
\text { aneurysms. }\end{array}$ & $\begin{array}{l}\text { Median approach and } \\
\text { good knowledge of } \\
\text { anatomy }\end{array}$ \\
\hline $\begin{array}{l}\text { CSF } \\
\text { Rhinorrhea }\end{array}$ & $\begin{array}{l}\text { Lumbar drainage } \\
\text { and secondary } \\
\text { repair if needed. }\end{array}$ & $\begin{array}{l}\text { Avoid damaging the } \\
\text { arachnoid and repair all } \\
\text { CSF leaks } \\
\text { intraoperatively }\end{array}$ \\
\hline $\begin{array}{l}\text { Sphenoid } \\
\text { Sinusitis }\end{array}$ & $\begin{array}{l}\text { Nasal steroids and } \\
\text { toilet }\end{array}$ & $\begin{array}{l}\text { Respect nasal anatomy. } \\
\text { Maintain the middle } \\
\text { turbinate, conserve the } \\
\text { nasal mucosa and gentle } \\
\text { post-operative nasal } \\
\text { packing that is removed } \\
\text { within 48 hours }\end{array}$ \\
\hline $\begin{array}{l}\text { Atrophic } \\
\text { Rhinitis }\end{array}$ & $\begin{array}{l}\text { Nasal hygiene and } \\
\text { care }\end{array}$ & $\begin{array}{l}\text { Avoid excessive damage } \\
\text { to nasal mucosa, tight } \\
\text { packing and regular } \\
\text { inspection of the nasal } \\
\text { cavity postoperatively }\end{array}$ \\
\hline $\begin{array}{l}\text { Nasal Septum } \\
\text { Perforation }\end{array}$ & $\begin{array}{l}\text { Surgical repair by } \\
\text { ENT surgeon }\end{array}$ & $\begin{array}{l}\text { Avoid damaging } \\
\text { turbinal and septal } \\
\text { mucosa which has ner } \\
\text { endings }\end{array}$ \\
\hline Olfactory & $\begin{array}{l}\text { Nasalose attention to } \\
\text { anatomy }\end{array}$ \\
\hline for adhesions & steroid and & $\begin{array}{l}\text { Avoid unnecessary } \\
\text { damage to nasal mucosa }\end{array}$ \\
\hline
\end{tabular}

\section{CONCLUSION}

The transnasal approach has made surgery for sellar lesions safer over the years. It has also evolved into a more versatile approach for skullbase lesions in expert hands. In this day and age, it would be prudent to collaborate with our ENT colleagues to improve patient outcomes and reduce complications.

\section{Conflict of Interest: None.}

\section{Authors' Contribution}

SSB: Conception, design, drafting and final approval, AK: Conception, design, drafting and final approval, MJ: Conception, design, drafting and final approval, MR: Conception and design.

\section{REFERENCES}

1. Marie P. Sur deuxcasd'acromégalie: hypertrophiesingulièrnon congénitale, des extrémitessupérieures, inférieures, et cephalique. Rev Med 1886; 6(1): 297-333.

2. Caton R, Paul FT. Notes of a case of acromegaly treated by operation. Br Med J 1893; 2(1): 1421-1423.

3. Horsley V. On the technique of operations on the central nervous-system. Br Med J 1906; 2(1): 411-423.

4. Collins WF: Hypophysectomy: historical and personal perspective. Clin Neurosurg 1974; 21: 68-78.

5. Couldwell WT, Simard MF, Weiss MH. Pituitary and adrenal,in Schwartz SI, Shires GT, Spencer FC (eds): Principles of Surgery, ed $7^{\text {th }}$. New York: Mc Graw-Hill 1999; 1(1): pp1613-1659.

6. Halstead AE. Remarks on the operative treatment of tumors ofthe hypophysis. With the report of two cases operated on by anoro-nasal method. Surg Gynecol Obstet 1910: 10(2): 494-502.

7. Hamlin H: Oskar Hirsch. Surg Neurol 1981: 16(2): 391-393.

8. Hirsch O. Endonasal method of removal of hypophysealtumors. With a report of two successful cases. J Am Med Assoc 1910; 55(2): 772-774.

9. Couldwell WT, Simard MF, Weiss MH. Pituitary and adrenal,in Schwartz SI, Shires GT, Spencer FC (eds): Principles ofSurgery,

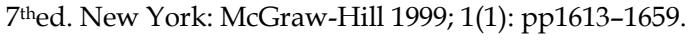

10. Welbourn RB. The evolution of transsphenoidal pituitary microsurgery. Surg 1986; 100(2): 1185-1190.

11. Laws ER. Pituitary surgery. Endocrin Metab Clin 1987; 16(3): 647-665.

12. Laws ER. Transsphenoidal microsurgery in the management of craniopharyngioma. J Neur 1980; 52(2): 661-666.

13. Wilson CB. A decade of pituitary microsurgery. The herbert olivecrona lecture. J Neur 1984; 61(1): 814-833.

14. Chandankhede VA, Singh SK, Roy R, Goyal S, Sridhar MS, Gill MS. Transnasal transsphenoidal approach for pituitary tumors: an ENT perspective. Ind J Otolaryngol Head Neck Surg 2020; 72(2): 239-246.

15. Zada G, Agarwalla PK, Mukundan S. The neurosurgicalanatomy of the sphenoid sinus and sellar floor in endoscopic transsphenoidal surgery. J Neur 2011; 114(2): 1319-1330.

16. Schaberg MR, Anand VK, Schwartz TH, Cobb W. Microscopic versus endoscopic transnasal pituitary surgery. Curr Opin Otolaryngol Head Neck Surg 2010; 18(1): 8-14.

17. Cheng Y, Xue F, Wang TY, Ji JF, Chen W, Wang ZY, et al. Analyses and treatments of postoperative nasal complications after endonasal transsphenoidal resection of pituitary neoplasms. Med (Baltimore) 2017; 96(15): e6614.

18. Hondronikos N, Alomari A, Schrader M, Knappe UJ. Rhinological consequences of microsurgical endonasal-transsphenoidal surgery for pituitary tumors. Exp Clin Endocrinol Diabetes 2021; 129(3): 157-62. 